\title{
Prevention Strategies and Interventions for Internet Use Disorders Due to Addictive Behaviors Based on an Integrative Conceptual Model
}

\author{
Seung-Yup Lee ${ }^{1} \cdot$ Min Seob Kim ${ }^{2} \cdot$ Hae Kook Lee ${ }^{3}$
}

Published online: 15 July 2019

(C) The Author(s) 2019

\begin{abstract}
Purpose of Review With increasing use of the Internet throughout our daily lives, Internet use disorders (IUDs) due to addictive behaviors are gaining recognition. As an umbrella term, IUD covers an array of online behaviors that are potentially addictive. The growing population of Internet and smartphone users also raised public health concerns over IUD in regard to adverse cognitive, developmental, psychosocial, and physical consequences. While scientific literature to date has tended to focus on specific forms of IUD such as gaming or pornography, confining our attention to only these specific areas may impede research on the combined effects of multiple online addictive behaviors - often the clinical reality in maladapted Internet use. Taking this broader approach may also facilitate prioritization in policymaking and more efficient allocation of public health and clinical resources. This paper discusses conceptual application of a public health model at the society level and an integrative model at the individual level in IUD intervention strategies. Current treatment modalities of IUD are also reviewed from a biopsychosocial perspective.

Recent Findings We propose that the harms of IUD are mediated by (1) risky/harmful content, (2) excessive/maladaptive use, and (3) financial burden. Prevention strategies that reduce the potential negative effects of these mediators may be useful against IUD. Summary Prevention and intervention efforts against IUD should not only target the "host" (individual vulnerabilities) but also the "agent" (media-related risks) and "environment" risks to better address complexities in the phenomena. The current mainstream therapeutic modality is psychosocial intervention. Further studies on psychopharmacology and neuromodulation are needed to broaden our therapeutic options for IUD.tf
\end{abstract}

Keywords Internet use disorders · Integrative conceptual model $\cdot$ Person-Affect-Cognition-Execution (I-PACE) model

\section{Introduction}

The Internet has become an integral part of modern society, with user populations continuing to grow across all age groups

This article is part of the Topical Collection on $I C D-11$

Hae Kook Lee

nplhk@ catholic.ac.kr

1 Department of Psychiatry, Eunpyeong St. Mary's Hospital, College of Medicine, The Catholic University of Korea, Seoul, Republic of Korea

2 Graduate School of Medical Science and Engineering, Korea Advanced Institute of Science and Technology (KAIST), Daejeon, Republic of Korea

3 Department of Psychiatry, Uijeongbu St. Mary's Hospital, College of Medicine, The Catholic University of Korea, 222 Banpo-daero, Seocho-gu, Seoul 06591, Republic of Korea
[1]. Over the past two decades, "Internet addiction" (IA) has emerged as a popular term and point of focus in research. Even though accurate assessment of IA is difficult due to a lack of uniform diagnostic criteria, recent estimates of IA prevalence have ranged from 0.7 to $20.0 \%$, depending on the year of study, location, measurement, and/or sample population [2-4]. Regardless, the overall problem size appears comparable with the problem size of other major mental disorders. Furthermore, addictive use of smartphones and other Internet-enabled devices may not be confined only to adolescents, but appears to affect all generations due to the rapid dissemination of smartphones and other information technologies across all ages $[1,5]$.

Some research has claimed that the Internet is merely a vector and not the actual source of addiction, suggesting that the term Internet addiction may be a misnomer [6]. Recognizing this debate, the category of Internet gaming disorder was included in Section III of the Diagnostic and 
Statistical Manual of Mental Disorders, Fifth Edition (DSM5) in 2013, as opposed to the general category of Internet use disorder, which was initially considered for inclusion in 2012. This development preceded recent plans to include gaming disorders in the upcoming eleventh revision of the World Health Organization (WHO) International Statistical Classification of Diseases and Related Health Problems [7]. Because experts recognize that there are many other online activities that may generate harm, however, a great deal of research continues in these other online activities.

For this reason, a lot of research employs the more general umbrella term of IUD. While there is not yet a consensus on the definition and scope of IUD, we suggest an important definitional parameter as follows. Internet use disorder (IUD) involves persistent online addictive behaviors that cause significant impairments in functioning. If the addictive behaviors also occur offline, then the online addictive behaviors should not be a mere continuation of the existing offline addictive behaviors, but a substantial portion of these maladaptive activities should be carried out by online means. Otherwise, more harmful consequences should emerge as a result of the maladaptive online activities in comparison with pre-existing offline addictive behaviors.

The scope of IUD appears to be quite broad, and some individuals may report multiple concurrent online-related problems. For example, individuals who report excessive/ maladaptive Internet use may not be limited only to online gaming or gambling but may also indulge in excessive use of social networking services (SNSs), pornography, shopping, web-surfing, and online video streaming. Research has shown that many of these activities may generate problems across multiple life areas. Gaming disorder and excessive use of social networking services have been shown to be associated with decreased academic performance and poor physical and mental health in younger populations [8-11]. Further, IA is significantly related to various forms of maladaptive behaviors such as substance use $[12,13]$, risky sexual behaviors [14], peer victimization [15], and suicidality [16, 17].

From our perspective, interventions for IUD should be tailored to specific online activities. Moreover, treatment outcomes are more likely to be beneficial when comprehensive buckets of individual factors (genetic, neurodevelopmental, personality, mental health, and motivations in users), environmental factors (socioeconomic background, cultural norms, accessibility, connection speed, monitoring systems, regulations, and policies), and agent factors (content, design, pricing, and marketing) are taken into account by an integrative model. To develop more effective intervention strategies, a holistic IUD prevention and treatment approach based on this integrative model should be used for better-targeted interventions. This review primarily aims to promote understanding of recent changes and to facilitate the development of health care policies and services against IUD. To develop effective IUD prevention strategies, we begin with a brief conceptual introduction of the integrative model. Next, preventive measures are reviewed based on a theoretical pathway model to harmful consequences of addictive behaviors in Internet use. Finally, we summarize recent findings of therapeutic interventions in different modalities.

\section{Intervention Strategies Based on a Conceptual Model for Internet Use Disorders}

To date, several useful conceptual models have attempted to summarize and integrate mechanisms that influence the development and continuation of addictive behaviors in Internet use [18]. Recently, the "tripartite neurocognitive model" has been proposed as a comprehensive approach to Internet gaming disorder. This model is based on neurobiological and neurocognitive research, which identifies abnormalities in bottom-up emotional regulatory functions of the amygdalastriatal area, top-down regulatory functions of the prefrontal cortex, and balancing functions in insular areas of the brain [19]. This theoretical model provides a basis for therapeutic intervention that aims to modulate impulsivity and emotional dysregulation in people with Internet gaming disorder. Another useful model is the Interaction of Person-AffectCognition-Execution (I-PACE) model, which attempts to integrate multiple psychological and neurological factors in explaining IUD [18]. The I-PACE model involves the components of affective state, cognitive style, and executive function, detailing some of the ways in which these variables may be appropriate areas for interventions, including psychotherapy, cognitive behavioral therapy, and biological treatment.

A common feature of the current models is the recognition of certain personal vulnerabilities that increase risks in developing IUD [20, 21]. For instance, users with neurotic traits may depend on SNSs to achieve social acceptance or reassurance. Preferences for certain game genres or specific Internet content may reflect differing psychological needs in vulnerable individuals [21-24]. Therefore, it is critical that these psychological factors are assessed and addressed in treatment.

From a public health perspective, IUDs have the potential to impact the well-being and health status of the general population, with some individuals being more at risk than others [25]. The epidemiological triad of host-agentenvironment explains how illness occurs in susceptible individuals. Illness occurs when an agent (as an external source of disease) encounters a vulnerable host, and when environmental factors allow interactions between the agent and the host [26]. This model suggests that it is necessary for interventions to target not only individuals but also the systems that support maladaptive behaviors [27]. This perspective on IUD also enables a broader 
understanding of how problems occur, which can be helpful for considering policy responses, such as those which have been implemented in some regions for gaming disorder $[28 \cdot \bullet]$.

With regard to the agent in this model, it is known that specific online content such as pornography or game genres, including multiple online role-playing games, may have higher addictive potential [29]. In research on problematic gaming, it is thought that certain game types may more readily foster maladaptive cognitions, such as automatic thoughts about game rewards or reliance on gaming activities, for identity needs $[30,31]$.

Individual psychosocial factors should also be considered in therapeutic planning [21]. Intrapersonal psychological factors such as low self-esteem, depression, and attention problems may act not only as predisposing factors but also as potentially modifiable targets of clinical intervention [32]. In addition to intrapersonal factors, assessment of interindividual aspects such as peer relationships, parent-child relationships, and social support may further help in establishing plans for treatment [32].

Environmental risk factors such as accessibility and industry-driven marketing factors may also serve as important targets for public health interventions [33]. It has been found that higher exposure to Internet game advertisements increases the risk for Internet game addiction among a representative sample of Korean youths [33]. Possession of easily accessible digital devices or a lack of parental rules about gaming behavior has been suggested as factors that influence the development of gaming disorder [31].

To summarize, individuals are generally at higher risk of developing IUDs when they are more exposed to risky online media, or when these activities are more available, as well as when individuals have predisposing biologic, cognitive, and psychological risk factors. In addition, environmental factors contribute to heightened IUD risk. Therefore, integrative intervention strategies including individual and environmental factors are needed.

\section{Internet Addiction Prevention Via Blocking Mediators to Harms in IUDs}

Two recent systemic reviews cover this topic [34, 35]. These reviews describe universal and selective prevention according to degree of vulnerability in target populations. While universal prevention applies to the general population, selective prevention is reserved for at-risk subpopulations with certain biologic, sociodemographic, and psychologic risk factors. For instance, health promotion campaigns advertised through traditional media channels are examples of universal prevention techniques, while specific programs such as screening for
IA or gaming problems in children would be examples of selective prevention.

In terms of targeting and in consideration of limited resources for prevention methods, selective prevention may have an edge over universal prevention insofar as it directly provides services to those at imminent or higher risk. However, selective prevention also has some limitations. Identification of risk factors is a prerequisite that may not always be feasible. Moreover, specialized approaches to different subgroups also require extensive resources.

Even further, universal prevention may reduce future risks of developing IUDs in populations without apparent risk factors. Considering the ubiquity of the Internet, which has effectively enabled "universal" access across different age groups of users [36, 37], this review focuses more on universal prevention of Internet misuse. We propose that the harms inflicted by Internet addiction are mainly mediated by (1) harmful content, (2) excessive/maladaptive use, and (3) financial costs (Fig. 1). Preventive strategies are discussed in regard to these mediators.

\section{Harmful Content}

Harmful content online may exert a negative impact on the mental health or psychosocial development of children due to exposure to inappropriate violent or sexual content. About $40 \%$ of male and $30 \%$ of female students have reported receipt of sexually explicit images through smartphones [38], and it has been shown that these "sexting" experiences are related to increased risks for unsafe sex [39]. Online sexual content may also become problematic in mature populations when the active seeking of this type of content intensifies and interferes with daily life. A recent survey in a representative German sample revealed that $4.2 \%$ of participants were identified as intensive Internet sexual users [40]. Recent findings on significantly increased ventral striatum activation in response to erotic stimuli in problematic users [41•], together with findings on how cognitive salience and cravings significantly influence the severity of Internet use problems, indicate the addictive nature of sexual content [42].

Negative mental consequences occur not only due to sexual content but also due to distressing content such as the live streaming of suicide or self-harm. Harmful content such as suicide coaching is abundant on the Internet [43]. Access to suicide promotion or self-harm websites is widespread [44]. Moreover, susceptible consumers may eventually become content "creators," posting their own self-mutilation videos or images. This has recently become a trend in Korean adolescents. In 2018, the Korea Ministry of Health and Welfare revealed startling results from a 2 -week period of monitoring 


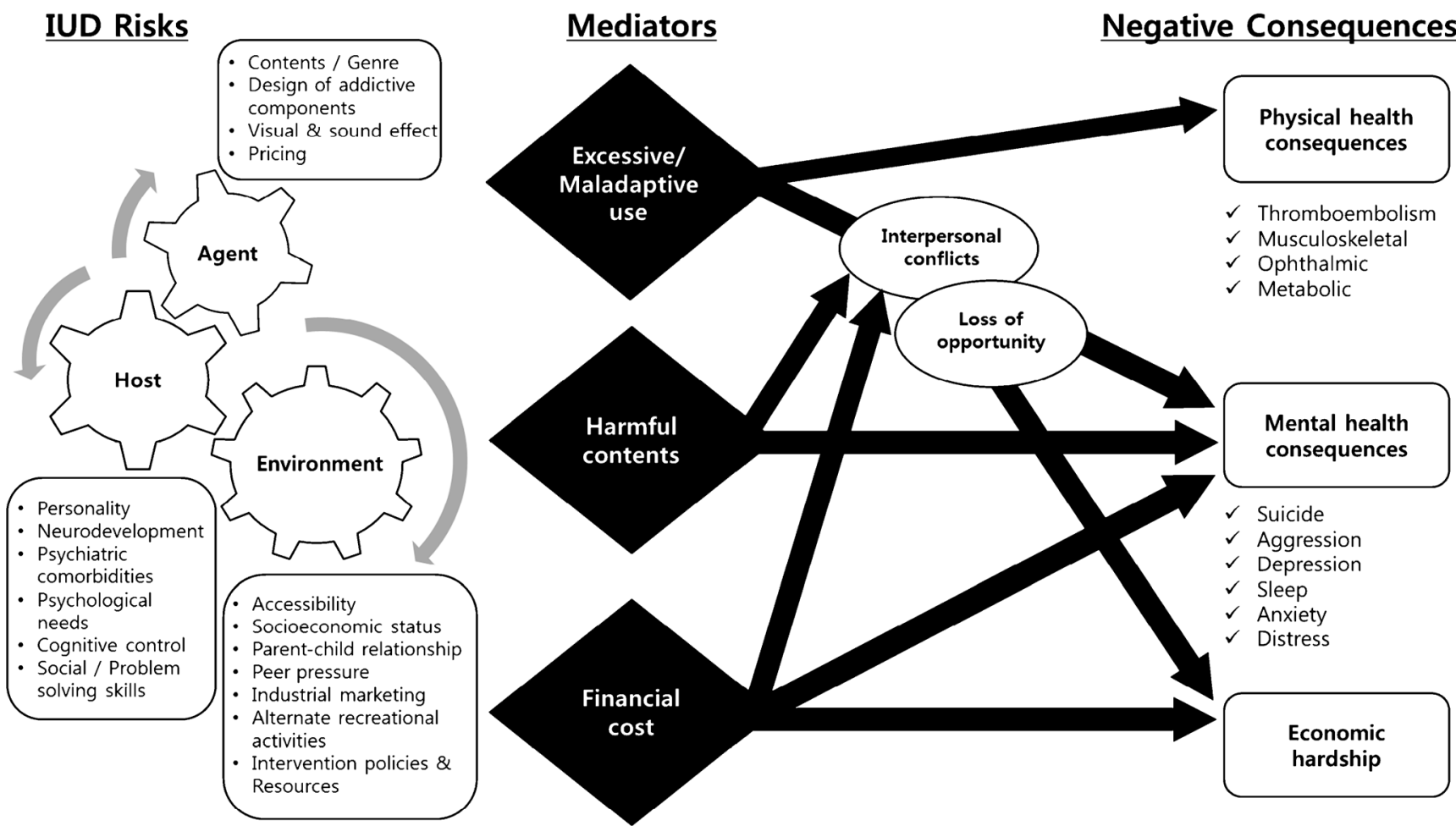

Fig. 1 Pathway model to IUD harmful consequences. IUD, Internet use disorder

suicide-related Internet videos or images. In this category, $84 \%$ of 8039 Internet videos or images involved self-mutilation, which is an increase of $3728 \%$ compared with 210 posts from the same monitoring period of the previous year [45]. In a recent systemic review, IUDs were found to be significantly related to both non-suicidal self-harm and suicidality [46]. In a Taiwanese study of 2479 high school students, both IUD and online exposure to suicidal content increased the risk of selfharm prior to adjustment for levels of self-esteem in participants, while only online exposure to suicidal content remained statistically significant following adjustment [47]. This important finding suggests the potential mediating role of harmful content to negative consequences of IUDs.

While television broadcasting or gaming products operate under an official rating system to determine appropriate user ages, websites, social networking services, or online streaming services often lack such official criteria for use eligibility. Thus, public policies are required to grade, monitor, and regulate online content. Mandating selfmonitoring and filtering systems by service providers (either through mechanisms of manpower or computer algorithms) are potential options [48]. Releasing official guidelines or strengthening legal enforcement of use eligibility may also prove to be effective. Moreover, legislative actions should be considered, requiring service providers of potentially harmful or addictive Internet content such as gambling or sexual content to adopt personal verification systems to restrict usage. However, caution is needed to avoid the potential violation of freedom of expression.

The European Monitoring Centre for Drugs and Drug Addiction (EMCDDA) previously recommended education about the negative consequences of IA and development of media skills to protect against IA by cooperating with parents, nursery schools, and primary/secondary schools. Additionally, the EMCDDA undertook the promotion of alternative recreational activities [49]. Four brief media literacy class education programs were reported to significantly reduce excessive online gaming in Germany [50]. To deliver effective programs, standardized program development and adequate training of teachers or counselors through qualified courses should be followed.

In addition to providing media education to children, prevention strategies may also directly target parents or guardians. Education and the heightening of parental media literacy are other important preventive efforts. In fact, a significant proportion of parents in a 2016 UK study (57\% and 52\% of parents of children aged 8 to 11 and 12 to 15 years of age, respectively) did not express concern about the online activities of their children [36]. Distribution of software or smartphone apps to monitor or limit access of minors to harmful content seems to be useful. Furthermore, providing instruction and/or user manuals to parents and guardians may additionally ensure effective utilization of healthy Internet behaviors on the part of younger users. 


\section{Excessive/Maladaptive Use}

IUD may lead to excessive time online at the expense of realworld activities. This, in turn, may jeopardize interpersonal relationships, career opportunities, and even the mental or physical health of people with IUDs (Fig. 1).

Gaming has become a major pastime for adolescents. A telephone interview of 1200 German teenagers by state media authorities revealed that respondents spent a daily average of $214 \mathrm{~min}$ on online activities, and that a quarter of this time was spent on playing games [5]. A US study of 15,624 adolescents revealed that, with increased time spent on "gaming or other non-academic computer use," mental health worsened in terms of higher depressive symptoms and suicide behaviors [51]. Reported time spent on Internet pornography has been shown to be significantly associated with compulsivity, while demonstrating negative correlations with sexual satisfaction [52]. Pathologic Internet use has been linked with suicidal behaviors and various mental health problems [53, 54], as well as with detrimental physical health features such as obesity, musculoskeletal pain, and poor oral health [55-57].

A direct prevention strategy for excessive use is access limitation. Access limitation is potentially highly effective, and many countries already prohibit the use of mobile phones while driving, or even while walking $[58,59]$. Nevertheless, stricter regulations including blocking, limiting screen time as a consequence of excessive use, or fatigue systems with mechanisms such as reduced connection speed past a certain point may bring controversy in regard to individual freedoms. Moreover, considering the anonymous nature of online activities, identifying users in order to block access may be prohibitively challenging.

Instead, we argue that such actions are more suitable for high-risk groups as techniques of selective prevention. For example, South Korea bans late-night entry of minors to Internet cafés or the access of minors to Internet gaming according to minors' own or parental requests [60]. The latter is called "selective shutdown" and is analogous to casino selfexclusion. In our opinion, expansion of these self-exclusion parameters should be considered for adults with mental health problems such as IUDs or intellectual disorder.

Self-blockage options by means of hardware or software are a promising potential prevention of Internet misuse. If this feature is pre-installed at the factory level, then users may find it easier to self-limit time online or the nature of the content they tend to access (e.g., self-limit late-night access). Apps that automatically track patterns of usage and provide feedback to users (or parents) may also be helpful [61]. Parental notifications on use patterns, alerts on hazardous access, the locking of certain apps, or the limiting of screen time may be effective preventive measures to protect children from IUDs or harmful Internet content $[62,63]$. South Korean law mandates mobile telecommunication service providers to pre- install filtering apps against harmful content on smartphones sold to minors, and enforces notification by providers to parents or guardians when apps become disabled for more than 15 days due to misuse on the part of minors [64]. This strategy is particularly valuable considering that "mobile gaming requires greater self-regulation skills" than stationary computer games [49].

\section{Financial Costs}

In addition to indirect costs due to opportunity loss from excessive use, IUDs may lead to direct financial costs due to online gambling, excessive expenditure on game items, or pornography. In social casino gaming, higher addiction scores have been shown to be associated with increased frequency of expenditures and social casino games spenders have been shown to have higher psychological distress $[65,66]$. In comparison with conventional gambling, online gambling may have more deleterious effects. Users may access illegal gambling websites with crooked gambling operation. Online gambling sites may be too easily accessible to children and adolescents. Taking advantage of the ubiquity of the Internet, which is unrestricted by time or space, the progression of online gambling problems may be accelerated compared with offline gambling.

Although financial consequences are often most severe in online gambling, uncontrolled compulsive expenditure on game items or pornographic content may also cause economic hardship to subjects with IUDs. The amount of money spent on purchasing "loot boxes" containing randomized game items has been shown to increase by gaming addiction severity in a dose-dependent manner [67]. These expenditures may become a financial burden in real life, and as a vicious cycle, the distress caused by real-world financial costs may further exacerbate IUD.

The UK Gambling Commission is reported to have considered a ban on the use of credit cards for online gambling [68]. In addition to banning online gambling credit card use as a method of universal prevention, we suggest that the introduction of self-measured options to limit or delay online transactions through electronic banking or mobile phone charges may be a useful strategy for selective prevention of IUD.

\section{Treatment}

Among specific types of IUDs, the greatest amount of therapeutic empirical evidence has been accumulated for gaming disorders because diagnostic formalization is the most imminent in this area of IUD. Still, no pharmacological doubleblind randomized controlled trials have been conducted for gaming disorders in contrast to gambling disorders [69]. 
Furthermore, there is no consensus on or formal clinical practice guidelines for gaming disorders [70]. Therefore, psychosocial intervention is currently regarded as the standard therapeutic modality. Methods of cognitive behavioral therapy (CBT), motivation interviewing (MI), family therapy, and boot camp (or some combination of these therapies) are deployed as treatment either individually or in group settings for subjects with IUD [71].

\section{Psychosocial Interventions}

CBT is the most commonly performed treatment method for addictive behaviors [72••]. Internet addiction CBT includes components of behavioral modification, cognitive therapy, and harm reduction therapy. The method challenges dysfunctional cognition and attempts to promote behavior changes by identification of false automatic thoughts, cognitive bias, and the coaching of alternate coping strategies. CBT has been shown to be effective not only in reducing symptoms but also in reducing comorbid depressive [73-75] and anxiety symptoms [75-79] in people with IUD. The number of CBT sessions is typically 8 to 12 sessions [72••]. Previous CBT studies have revealed that treatment for Internet addiction is generally more effective in adult populations than in adolescents [72••]. Although it remains unclear whether individual or group CBT is more effective, group therapy is reported more often in youths than in adults [72••]. Although effective, CBT mainly addresses the intrapersonal vulnerability of individual risk factors. Therefore, in addition to maladaptive cognitive style in subjects with IUD, executive functions, mood, interpersonal problems, and vulnerability due to environmental factors should also be evaluated.

Family therapy is an important therapeutic intervention in IUD. Family structure, level of functioning, and family dynamics may greatly influence the development of IUD. Family conflict or poor family functioning are known environmental risk factors associated with IUD in adolescents [80]. In one existing study, gaming disorder symptoms and game-playing duration were reported to be significantly reduced in participants following five sessions of family therapy [81]. The program consisted of (1) family functioning and cohesion evaluation, (2) activities to strengthen family cohesion, (3) healthy communication about the activities, and (4) the receipt of rewards for positive behaviors [81].

Other potential psychosocial treatments are motivation interviewing, mindfulness-based cognitive therapy, and/or a combination of these therapies [71].

\section{Boot Camp (Therapeutic Residential Programs)}

The first boot camp for IUD, "Jump Up Internet Rescue School," was introduced by a government agency known as the Korea Youth Counseling Institute in 2007. It was reported that, following 12 days of a residential program comprising education and alternative recreational activities, participants showed significant improvement on self-reported and parentscored IA scales, as well as in other self-measures for gaming, depression, sense of well-being, and self-control [82]. In Japan, a boot camp program has also demonstrated effectiveness in reducing time spent on online gaming among adolescents [83].

These boot camp programs seem to offer several advantages in comparison with outpatient settings. Considering that most subjects with IUD have their own personal access to the Internet or gaming devices, physical separation from these objects of enablement may act as detoxification. Upon separation from online connectivity, IUD subjects may be able to experience and build interpersonal relationships in the real world. Moreover, boot camps may serve as a space to provide intensive psychoeducation or CBT programs to IUD patients.

\section{Pharmacotherapy}

The most commonly studied pharmacotherapy for addictive behaviors is antidepressants [71]. However, evidence of the effectiveness of antidepressants is limited due to small sample sizes and due to a lack of randomized double-blind studies. Both bupropion and escitalopram have been shown to be effective in improving gaming disorder symptoms but bupropion tends to be more effective in reducing impulsivity [84]. Although evidence exists at the level of case reports only, naltrexone has also been reported to be effective against compulsive use of Internet pornography $[85,86]$.

\section{Neuromodulation}

Growing attention has been given to noninvasive brain stimulation techniques in addictive disorders as novel therapeutic modalities. Noninvasive brain stimulation techniques of repeated transcranial magnetic stimulation (rTMS) and transcranial direct current stimulation (tDCS) have demonstrated significant effects in controlling of substance or food cravings $[87,88]$.

Two randomized sham-controlled rTMS studies were conducted in subjects with gambling disorders. Although evaluated in the context of conventional gambling disorders, rTMS was shown to significantly reduce cue-induced cravings in subjects [89]. Another clinical study, however, failed to demonstrate a significant difference in treatment efficacy in comparison with the sham [90]. These contradicting results demonstrate the need for further studies to examine the clinical utility of this type of neuromodulation in online gambling.

In an open-label study of online gamers, tDCS significantly reduced gaming time and Internet addiction scores, while increasing self-control in subjects [91]. Although the effectiveness of tDCS was demonstrated only in gaming behavior, if 
future studies on other forms of IUD prove to have clinical utility, then the diversity of therapeutic options for subjects with IUD may expand.

Diverse therapeutic options have the potential to better intervene according to different components of the integrated IUD model. To date, there have been relatively few studies on IUD treatment compared with the numerous epidemiologic studies in IUD. Most of the existing treatment studies cover psychosocial interventions. Future well-designed studies are required to offer prevention strategies and interventions based on biological risk factors.

\section{Conclusion}

With the ubiquity of high-speed Internet connection and widespread use of smartphones, public health problems due to maladaptive or addictive use of information technologies are anticipated to increase. In contrast, prevention and treatment of IUDs face many challenges in today's world for the following reasons. First, there is a shortage in scientific literature about the topic. Insofar as concepts of behavioral addiction and IUD are relatively new, there is scarcity in empirical studies on prevention or treatment for addictive behaviors in subjects with various forms of IUD. Current evidence exists mainly in the context of online gaming disorders or IA in general [34, 71]. More research is needed in other forms of IUD. Second, due to astonishing speed in the development of information technologies, a time lag between new technologies and interventions is always likely to exist. Furthermore, the worldwide, borderless nature of Internet access makes it more difficult (if not impossible) for any single country to mitigate every channel of hazardous online media, which are being constantly created and uploaded across the globe. Along these lines, international collaborations are crucial for efficacy in preventive efforts toward IUD.

Despite these restrictions, allied health professionals need to address problems in individuals impacted by IUD to improve their health and well-being. An integrative approach based on a public health model of IUD may lead to better outcomes than attempts thus far to manage contributors separately. In terms of the epidemiological triad of host-agent-environment, a comprehensive approach to IUD involves several aspects of diagnosis and treatment. As an "agent," online media should be scrutinized to determine which of its characteristics reinforce compulsive or maladaptive use of the Internet. Predisposing biologic, cognitive, and psychological vulnerabilities of a "host," together with the host's interactions with the agent and the "environment" should all be considered in robust assessment and interventional measures for IUD.
Provision of education, screening, and early intervention are important aspects of IUD prevention. Such interventions are mainly applicable to hosts, however, even though preventive measures against the agent and the environment are requirements of effective prevention. Therefore, we suggest the application of more active means of intervention toward the mediators of harms in IUDs, instead of directing efforts only toward the host.

Development of strategies to create safer environments in Internet use is crucial to address IUD. A public or mandatory corporate system of grading, monitoring, and blocking and/or filtering harmful content may reduce the detrimental effects of online media to the mental health of users. However, considering that only marginally protective effects have been shown in limiting children's exposure to Internet sexual content, further well-designed prospective studies are needed to develop effective methods [92]. In addition to these types of protective mechanisms, the provision of easy parental instructions on how to utilize monitoring or filtering against harmful media use is also necessary.

Regulations to create a less harmful "agent" may face strong opposition from the information technology industry. Nevertheless, policymaking efforts are needed to establish industry-level auto-regulations, such as providing options for self-blockage via hardware or software mechanisms, analogous to casino-exclusion. Limiting or delaying electronic transactions for online expenditures could be useful to mitigate the financial burden of some forms of IUD. If the removal of self-blockage on monetary transactions involves some time delay (i.e., 12 to $24 \mathrm{~h}$ ), this may protect against impulsive urges, and in turn, reduce the economic consequences of excessive expenditure online.

With constant development in information technologies and the expansion of online media, effective preventive and intervention plans to reduce the harms of IUD are critical. Application of the IUD public health model to strengthen preventive efforts toward the "agent" and the "environment" for intervention against harmful IUD pathways is a costeffective preventive strategy. Our review of existing literature indicates that current treatment methods mainly focus on psychosocial interventions, while more active research on biological interventions may broaden our options for intervention against IUD.

Acknowledgements This study was supported by a grant from the Korean Mental Health Technology R\&D Project, Ministry of Health and Welfare, Republic of Korea (HM15C1124).

\section{Compliance with Ethical Standards}

Conflict of Interest The authors declare that they have no conflicts of interest. 
Human and Animal Rights and Informed Consent This article does not contain any studies with human or animal subjects performed by any of the authors.

Open Access This article is distributed under the terms of the Creative Commons Attribution 4.0 International License (http:// creativecommons.org/licenses/by/4.0/), which permits unrestricted use, distribution, and reproduction in any medium, provided you give appropriate credit to the original author(s) and the source, provide a link to the Creative Commons license, and indicate if changes were made.

\section{References}

Papers of particular interest, published recently, have been highlighted as:

- Of importance

- Of major importance

1. Ministry of Science and ICT, Korea Internet \& Security Agency. 2017 Survey on the Internet Usage 2018

2. Wu CY, Lee MB, Liao SC, Ko CH. A nationwide survey of the prevalence and psychosocial correlates of internet addictive disorders in Taiwan. J Formos Med Assoc. 2019;118(1 Pt 3):514-23. https://doi.org/10.1016/j.jfma.2018.10.022.

3. Modara F, Rezaee-Nour J, Sayehmiri N, Maleki F, Aghakhani N, Sayehmiri K, et al. Prevalence of Internet addiction in Iran: a systematic review and meta-analysis. Addict Health. 2017;9(4):24352 .

4. Gomez P, Rial A, Brana T, Golpe S, Varela J. Screening of problematic Internet use among Spanish adolescents: prevalence and related variables. Cyberpsychol Behav Soc Netw. 2017;20(4): 259-67.

5. Feierrabend S, Rathgeb T, Reutter T. JIM Studie. Stuttgart: Medienpädagogische Forschungsverbund Südwest; 2018. p. 2018.

6. Starcevic V. Is Internet addiction a useful concept? Aust N Z J Psychiatry. 2013;47(1):16-9.

7. World Health Organization. ICD-11 Beta Draft (Mortality and Morbidity Statistics). URL: http://apps.who.int/classifications/ icd11/browse/lm/en. Accessed 19 May 2019.

8. Tran BX, Hinh ND, Nguyen LH, Le BN, Nong VM, Thuc VTM, et al. A study on the influence of internet addiction and online interpersonal influences on health-related quality of life in young Vietnamese. BMC Public Health. 2017;17(1):138.

9. Ho RC, Zhang MW, Tsang TY, Toh AH, Pan F, Lu Y, et al. The association between internet addiction and psychiatric co-morbidity: a meta-analysis. BMC Psychiatry. 2014;14(1):183.

10. van den Eijnden R, Koning I, Doornwaard S, van Gurp F, Ter Bogt T. The impact of heavy and disordered use of games and social media on adolescents' psychological, social, and school functioning. J Behav Addict. 2018;7(3):697-706.

11. Marin Vila M, Carballo Crespo JL, Coloma Carmona A. Academic outcomes and cognitive performance in problematic Internet users. Adicciones. 2018;30(2):101-10.

12. Di Nicola M, Ferri VR, Moccia L, Panaccione I, Strangio AM, Tedeschi D, et al. Gender differences and psychopathological features associated with addictive behaviors in adolescents. Front Psychiatry. 2017;8:256.

13. Lee YS, Han DH, Kim SM, Renshaw PF. Substance abuse precedes internet addiction. Addict Behav. 2013;38(4):2022-5.
14. Shapiro GK, Tatar O, Sutton A, Fisher W, Naz A, Perez S, et al. Correlates of tinder use and risky sexual behaviors in young adults. Cyberpsychol Behav Soc Netw. 2017;20(12):727-34.

15. Martinez-Ferrer B, Moreno D, Musitu G. Are adolescents engaged in the problematic use of social networking sites more involved in peer aggression and victimization? Front Psychol. 2018;9:801.

16. Kim B-S, Chang SM, Park JE, Seong SJ, Won SH, Cho MJ. Prevalence, correlates, psychiatric comorbidities, and suicidality in a community population with problematic Internet use. Psychiatry Res. 2016;244:249-56.

17. Guo L, Luo M, Wang WX, Huang GL, Xu Y, Gao X, et al. Association between problematic Internet use, sleep disturbance, and suicidal behavior in Chinese adolescents. J Behav Addict. 2018;7(4):965-75.

18. Brand M, Young KS, Laier C, Wölfling K, Potenza MN. Integrating psychological and neurobiological considerations regarding the development and maintenance of specific Internet-use disorders: an Interaction of Person-Affect-Cognition-Execution (I-PACE) model. Neurosci Biobehav Rev. 2016;71:252-66.

19. Wei L, Zhang S, Turel O, Bechara A, He Q. A tripartite neurocognitive model of Internet gaming disorder. Front Psychiatry. 2017;8:285.

20. Billieux J, Maurage P, Lopez-Fernandez O, Kuss DJ, Griffiths MD. Can disordered mobile phone use be considered a behavioral addiction? An update on current evidence and a comprehensive model for future research. Curr Addict Rep. 2015;2(2):156-62.

21. Lee SY, Lee HK, Choo H. Typology of Internet gaming disorder and its clinical implications. Psychiatry Clin Neurosci. 2017;71(7): 479-91.

22. Lee M-S, Ko Y-H, Song H-S, Kwon K-H, Lee H-S, Nam M, et al. Characteristics of Internet use in relation to game genre in Korean adolescents. Cyber Psychol Behav. 2006;10(2):278-85.

23. Eichenbaum A, Kattner F, Bradford D, Gentile DA, Green CS. Role-playing and real-time strategy games associated with greater probability of Internet gaming disorder. Cyberpsychol Behav Soc Netw. 2015;18(8):480-5.

24. Kim JW, Han DH, Park DB, Min KJ, Na C, Won SK, et al. The relationships between online game player biogenetic traits, playing time, and the genre of the game being played. Psychiatry Investig. 2010;7(1):17-23.

25. World Health Organization. Public health implications of excessive use of the internet, computers, smartphones and similar electronic devices: Meeting report. Tokyo, Japan; 2015.

26. Gulis G, Fujino Y. Epidemiology, population health, and health impact assessment. J Epidemiol. 2015;25(3):179-80.

27. Messerlian C, Derevensky J, Gupta R. Youth gambling problems: a public health perspective. Health Promot Int. 2005;20(1):69-79.

28.• Király O, Griffiths MD, King DL, Lee H-K, Lee S-Y, Bányai F, et al. Policy responses to problematic video game use: a systematic review of current measures and future possibilities. J Behav Addict. 2018;7(3):503-17. https://doi.org/10.1556/2006.6.2017.050. This study thoroughly reviews various policies against problematic gaming worldwide and suggests potential measures for further development.

29. Elliott L, Ream G, McGinsky E, Dunlap E. The contribution of game genre and other use patterns to problem video game play among adult video gamers. Int J Ment Heal Addict. 2012;10(6): 948-69.

30. Beard CL, Wickham RE. Gaming-contingent self-worth, gaming motivation, and Internet gaming disorder. Comput Hum Behav. 2016;61:507-15.

31. King DL, Delfabbro PH. The cognitive psychology of Internet gaming disorder. Clin Psychol Rev. 2014;34(4):298-308.

32. Koo HJ, Kwon JH. Risk and protective factors of internet addiction: a meta-analysis of empirical studies in Korea. Yonsei Med J. 2014;55(6):1691-711. 
33. Chung S, Lee J. Exposure to internet game advertisements and the risk of internet game addiction among youths. Korean J Health Educ Promot. 2017;34(3):47-57.

34. Vondráčková P, Gabrhelik R. Prevention of Internet addiction: a systematic review. J Behav Addict. 2016;5(4):568-79.

35. King DL, Delfabbro PH, Doh YY, Wu AMS, Kuss DJ, Pallesen S, et al. Policy and prevention approaches for disordered and hazardous gaming and Internet use: an international perspective. Prev Sci. 2018;19(2):233-49.

36. Livingstone S, Davidson J, Bryce J, Batool S, Haughton C, Nandi A. Children's online activities, risks and safety a literature review by the UKCCIS Evidence Group. London: UK Council for Child Internet Safety; 2017. p. 110.

37. Center PR. Internet/broadband fact sheet Washington: Pew Research Center. Available from: http://www.pewinternet.org/ fact-sheet/internet-broadband/. Accessed 20 May 2019.

38. Strassberg DS, Cann D, Velarde V. Sexting by high school students. Arch Sex Behav. 2017;46(6):1667-72.

39. Rice E, Gibbs J, Winetrobe H, Rhoades H, Plant A, Montoya J, et al. Sexting and sexual behavior among middle school students. Pediatrics. 2014;134(1):e21-8.

40. Beutel ME, Giralt S, Wolfling K, Stobel-Richter Y, Subic-Wrana C, Reiner I, et al. Prevalence and determinants of online-sex use in the German population. PLoS One. 2017;12(6):e0176449.

41. Gola M, Wordecha M, Sescousse G, Lew-Starowicz M, Kossowski B, Wypych M, et al. Can pornography be addictive? An fMRI study of men seeking treatment for problematic pornography use. Neuropsychopharmacology. 2017;42(10):2021-31. This functional imaging study demonstrates that excessive pornography use shares neurobiologic and behavioral mechanisms with other addictive disorders by higher activation of ventral striatum to erotic cues compared with monetary cues.

42. Pekal J, Laier C, Snagowski J, Stark R, Brand M. Tendencies toward Internet-pornography-use disorder: differences in men and women regarding attentional biases to pornographic stimuli. J Behav Addict. 2018;7(3):574-83.

43. Chen YY, Hung GC, Cheng Q, Tsai CW, Wu KC. Searching for suicide-related information on Chinese websites. Psychiatry Res. 2017;258:506-10.

44. Mars B, Heron J, Biddle L, Donovan JL, Holley R, Piper M, et al. Exposure to, and searching for, information about suicide and selfharm on the Internet: prevalence and predictors in a population based cohort of young adults. J Affect Disord. 2015;185:239-45.

45. Chu M. Online pictures, videos on suicide, self-harm spiked 3, 728\% in 2018: Korea Biomedical Review. Available from: http:// www.koreabiomed.com/news/articleView.html?idxno=4025. Accessed 2 Jun 2019.

46. Steinbuchel TA, Herpertz S, Kulpmann I, Kehyayan A, DierisHirche J, Te Wildt BT. Internet addiction, suicidality and nonsuicidal self-harming behavior - a systematic review. Psychother Psychosom Med Psychol. 2018;68(11):451-61.

47. Liu HC, Liu SI, Tjung JJ, Sun FJ, Huang HC, Fang CK. Self-harm and its association with internet addiction and internet exposure to suicidal thought in adolescents. J Formos Med Assoc. 2017;116(3): 153-60.

48. Quinn B. Javid: tech firms not taking online child sexual abuse seriously: the Guardian. Available from: https://www.theguardian. com/society/2018/sep/03/javid-tech-firms-not-taking-online-childsexual-abuse-seriously. Accessed 2 Jun 2019.

49. European Monitoring Centre for Drugs and Drug Addiction. Prevention of addictive behaviours. German Federal Centre for Health Education. 2015. available from: http://www.emcdda. europa.eu/system/files/publications/1813/TDXD15018ENN_1. pdf.

50. Walther B, Hanewinkel R, Morgenstern M. Effects of a brief school-based media literacy intervention on digital media use in adolescents: cluster randomized controlled trial. Cyberpsychol Behav Soc Netw. 2014;17(9):616-23.

51. Lee HH, Sung JH, Lee JY, Lee JE. Differences by sex in association of mental health with video gaming or other nonacademic computer use among US adolescents. Prev Chronic Dis. 2017;14:E117.

52. Blais-Lecours S, Vaillancourt-Morel MP, Sabourin S, Godbout N. Cyberpornography: time use, perceived addiction, sexual functioning, and sexual satisfaction. Cyberpsychol Behav Soc Netw. 2016;19(11):649-55.

53. Guo L, Luo M, Wang WX, Huang GL, Xu Y, Gao X, et al. Association between problematic Internet use, sleep disturbance, and suicidal behavior in Chinese adolescents. J Behav Addict. 2018;7(4):965-75. https://doi.org/10.1556/2006.7.2018.115.

54. Kaess M, Durkee T, Brunner R, Carli V, Parzer P, Wasserman C, et al. Pathological Internet use among European adolescents: psychopathology and self-destructive behaviours. Eur Child Adolesc Psychiatry. 2014;23(11):1093-102.

55. Bozkurt H, Ozer S, Sahin S, Sonmezgoz E. Internet use patterns and Internet addiction in children and adolescents with obesity. Pediatr Obes. 2018;13(5):301-6.

56. Do KY, Lee KS. Relationship between problematic Internet use, sleep problems, and oral health in Korean adolescents: a national survey. Int J Environ Res Public Health. 2018;15(9):1870. https:// doi.org/10.3390/ijerph15091870.

57. AlAbdulwahab SS, Kachanathu SJ, AlMotairi MS. Smartphone use addiction can cause neck disability. Musculoskeletal Care. 2017;15(1):10-2.

58. Matyszczyk C. France bans drivers from using phones, even when stopped: Cnet. Available from: https://www.cnet.com/news/frenchcellphone-law-means-drivers-cant-just-pull-over-to-talk/. Accessed 3 Jun 2019.

59. Gibbs S. Honolulu now fines people up to $\$ 99$ for texting while crossing road. The Guardian. Available from: https://www. theguardian.com/technology/2017/oct/25/honolulu-fines-peoplefor-texting-while-crossing-road. Accessed 3 Jun 2019.

60. Lee HK, Lee S-Y, Lee BH, Kim EB. Comparative investigation of prevention policy on Internet game addiction problems. Seoul: Gender Equality and Family Committee, National Assembly; 2017.

61. Fowler B. How to use the parental controls on a smartphone: consumer reports. Available from: https://www.consumerreports.org/ smartphones/how-to-use-parental-controls-on-a-smartphone/. Accessed 5 Jun 2019.

62. Tibken S. Apple's new Families page details ways to monitor kids' iPhone use: Cnet. Available from: https:/www.cnet.com/news/ apples-iphone-families-page-details-ways-to-monitor-kids-deviceuse/. Accessed 5 Jun 2019.

63. Field M. Google launches new tools to let parents turn off their teenager's smartphone remotely: the Telegraph. Available from: https:/www.telegraph.co.uk/technology/2018/09/19/googleslaunches-new-tools-let-parents-turn-teenagers-smartphones/. Accessed 5 Jun 2019.

64. Methods of and Procedures for Block of Media Products, etc. Harmful to Juveniles (Enforcement decree of the telecommunications business Act), $3 \S 37-8$. 2015. Retrieved from http://www. law.go.kr/LSW/eng/engLsSc.do?menuId=2\&query=\#EJP34:0.

65. Gainsbury SM, King DL, Russell AM, Delfabbro P, Hing N. Virtual addictions: an examination of problematic social casino game use among at-risk gamblers. Addict Behav. 2017;64:334-9.

66. King DL, Russell A, Gainsbury S, Delfabbro PH, Hing N. The cost of virtual wins: an examination of gambling-related risks in youth who spend money on social casino games. J Behav Addict. 2016;5(3):401-9.

67. Zendle D, Cairns P. Video game loot boxes are linked to problem gambling: results of a large-scale survey. PLoS One. 2018;13(11): e0206767. 
68. Davies R. Gambling on credit cards could be banned in overhaul of betting: The Guardian. 2019. Retrieved from https://www. theguardian.com/society/2019/jan/12/gambling-on-credit-cardscould-be-banned-in-overhaul-of-betting.

69. Dullur P, Hay P. Problem Internet use and Internet gaming disorder: a survey of health literacy among psychiatrists from Australia and New Zealand. Aust Psychiatry. 2017;25(2):140-5.

70. King DL, Haagsma MC, Delfabbro PH, Gradisar M, Griffiths MD. Toward a consensus definition of pathological video-gaming: a systematic review of psychometric assessment tools. Clin Psychol Rev. 2013;33(3):331-42.

71. King DL, Delfabbro PH, Wu AM, Doh YY, Kuss DJ, Pallesen S, et al. Treatment of Internet gaming disorder: an international systematic review and CONSORT evaluation. Clin Psychol Rev. 2017;54:123-33.

72.• Stevens MW, King DL, Dorstyn D, Delfabbro PH. Cognitivebehavioral therapy for Internet gaming disorder: A systematic review and meta-analysis. Clinical Psychology \& Psychotherapy. 2019;26(2):191-203. https://doi.org/10.1002/cpp.2341. This meta-analysis demonstrated that cognitive-behavioural therapy is effective in reducing gaming disorder symptoms but not for actual gaming time.

73. Lee JH, Son $\mathrm{CN}$. The effects of the group cognitive behavioral therapy on game addiction level, depression and self-control of the high school students with internet game addiction. Korean J Stress Res. 2008;16:409-18.

74. Wölfling K, Beutel M, Dreier M, Müller K. Treatment outcomes in patients with internet addiction: a clinical pilot study on the effects of a cognitive-behavioral therapy program. Biomed Res Int. 2014;2014:1-8.

75. Santos VA, Freire R, Zugliani M, Cirillo P, Santos HH, Nardi AE, et al. Treatment of internet addiction with anxiety disorders: treatment protocol and preliminary before-after results involving pharmacotherapy and modified cognitive behavioral therapy. JMIR Res Protoc. 2016;5(1):e46.

76. Cao F, Linyan S, Gao X. Control study of group psychotherapy on middle school students with Internet overuse. Chin Ment Health J. 2007;21(05):346-9.

77. Y-s D, Jiang W, Vance A. Longer term effect of randomized, controlled group cognitive behavioural therapy for Internet addiction in adolescent students in Shanghai. Aust N Z J Psychiatry. 2010;44(2): 129-34.

78. Kim SM, Han DH, Lee YS, Renshaw PF. Combined cognitive behavioral therapy and bupropion for the treatment of problematic on-line game play in adolescents with major depressive disorder. Comput Hum Behav. 2012;28(5):1954-9.

79. Li H, Wang S. The role of cognitive distortion in online game addiction among Chinese adolescents. Child Youth Serv Rev. 2013;35(9):1468-75.

80. Young $\mathrm{K}$. Understanding online gaming addiction and treatment issues for adolescents. Am J Fam Ther. 2009;37(5):355-72.

81. Han DH, Kim SM, Lee YS, Renshaw PF. The effect of family therapy on the changes in the severity of on-line game play and brain activity in adolescents with on-line game addiction. Psychiatry Res Neuroimaging. 2012;202(2):126-31.
82. Koo C, Wati Y, Lee CC, Oh HY. Internet-Addicted Kids and South Korean Government Efforts: Boot-Camp Case. Cyberpsychology, Behavior, and Social Networking. 2011;14(6):391-4. https://doi. org/10.1089/cyber.2009.0331.

83. Sakuma H, Mihara S, Nakayama H, Miura K, Kitayuguchi T, Maezono M, et al. Treatment with the self-discovery camp (SDiC) improves internet gaming disorder. Addict Behav. 2017;64:357-62.

84. Song J, Park JH, Han DH, Roh S, Son JH, Choi TY, et al. Comparative study of the effects of bupropion and escitalopram on Internet gaming disorder. Psychiatry Clin Neurosci. 2016;70(11):527-35. https://doi.org/10.1111/pcn.12429.

85. Capurso NA. Naltrexone for the treatment of comorbid tobacco and pornography addiction. Am J Addict. 2017;26(2):115-7.

86. Kraus SW, Meshberg-Cohen S, Martino S, Quinones LJ, Potenza MN. Treatment of compulsive pornography use with naltrexone: a case report. Am J Psychiatr. 2015;172(12):1260-1. https://doi.org/ 10.1176/appi.ajp.2015.15060843.

87. Lupi M, Martinotti G, Santacroce R, Cinosi E, Carlucci M, Marini $\mathrm{S}$, et al. Transcranial direct current stimulation in substance use disorders: a systematic review of scientific literature. J ECT. 2017;33(3):203-9. https://doi.org/10.1097/YCT. 0000000000000401 .

88. Sauvaget A, Trojak B, Bulteau S, Jimenez-Murcia S, FernandezAranda F, Wolz I, et al. Transcranial direct current stimulation (tDCS) in behavioral and food addiction: a systematic review of efficacy, technical, and methodological issues. Front Neurosci. 2015;9:349. https://doi.org/10.3389/fnins.2015.00349.

89. Gay A, Boutet C, Sigaud T, Kamgoue A, Sevos J, Brunelin J, et al. A single session of repetitive transcranial magnetic stimulation of the prefrontal cortex reduces cue-induced craving in patients with gambling disorder. Eur Psychiatry. 2017;41:68-74. https://doi.org/ 10.1016/j.eurpsy.2016.11.001.

90. Sauvaget A, Bulteau S, Guilleux A, Leboucher J, Pichot A, Valriviere $\mathrm{P}$, et al. Both active and sham low-frequency rTMS single sessions over the right DLPFC decrease cue-induced cravings among pathological gamblers seeking treatment: a randomized, double-blind, sham-controlled crossover trial. J Behav Addict. 2018;7(1):126-36. https://doi.org/10.1556/2006.7.2018.14

91. Lee SH, Im JJ, Oh JK, Choi EK, Yoon S, Bikson M, et al. Transcranial direct current stimulation for online gamers: a prospective single-arm feasibility study. J Behav Addict. 2018;7(4): 1166-1170. https://doi.org/10.1556/2006.7.2018.107.

92. Przybylski AK, Nash V. Internet filtering and adolescent exposure to online sexual material. Cyberpsychol Behav Soc Netw. 2018;21(7):405-10. https://doi.org/10.1089/cyber.2017.0466.

Publisher's Note Springer Nature remains neutral with regard to jurisdictional claims in published maps and institutional affiliations. 